\title{
Administration of Chemotherapy in University Clinical Center of Kosova by Nurses
}

\author{
Vlora Ejupi ${ }^{1}{ }^{*}$, Shqipe Tahiri², Idriz Sopjani ${ }^{2}$ \\ ${ }^{1}$ Clinic of Hematology, University Clinical Center of Kosovo, Pristina, Kosovo \\ ${ }^{2}$ Faculty of Nursing, AAB College, Pristina, Kosovo \\ Email: *vlora.fejzullahu@universitetiaab.com
}

How to cite this paper: Ejupi, V., Tahiri, S. and Sopjani, I. (2020) Administration of Chemotherapy in University Clinical Center of Kosova by Nurses. Open Journal of Nursing, 10, 513-525.

https://doi.org/10.4236/ojn.2020.105035

Received: February 4, 2020

Accepted: May 19, 2020

Published: May 22, 2020

Copyright () 2020 by author(s) and Scientific Research Publishing Inc. This work is licensed under the Creative Commons Attribution International License (CC BY 4.0).

http://creativecommons.org/licenses/by/4.0/

(c) (i) Open Access

\begin{abstract}
Policy development on chemotherapy management has increased the demand for deeper knowledge in this field. In this way, there was a need to identify, recognize the consumption trends of chemotherapeutic and prioritize the interest of regulatory bodies, as well as to design programs for health education. In 1978 for the first time in Kosovo, a Hematology Department was established within the Internal Diseases Clinic by Dr. Shaban Geci. In 2013 it became a Clinic of Hematology. The Department of Clinical Hematology deals with the diagnosis of hematologic and hematopoietic diseases including erythrocytes, leukocytes, platelets as well as malignant diseases. Within the department is also the location for puncture and biopsy of the bone marrow as well as for ultrasonography. Methods: The study was prospective and was conducted at University Clinical Center of Kosova (UCCK) and is based on an anonymous survey designed specifically for this purpose. The subject of the analysis was the available space for hospitalization and administration of chemotherapeutic at UCCK, the existence or not of written protocols, and available technical equipment. Results: Respondents were asked how many nurses handle the administration of cytostatic at the clinic where they work. $48 \%$ of respondents state that 1 - 5 nurses deal with cytostatic administration, $52 \%$ of respondents say 1 - 15 nurses deal with cytostatic administration, while alternatives $6-10$ nurses and 16 and more nurses were not selected by no respondents.
\end{abstract}

\section{Keywords}

UCCK, Chemotherapy, Nurses, Standards, Cancer

\section{Introduction}

\subsection{Overview of the Administration of Chemotherapeutics}

Policy development on chemotherapy management has increased the demand 
for deeper knowledge in this field. In this way, there was a need to identify, recognize the consumption trends of chemotherapeutics and prioritize the interest of regulatory bodies, as well as to design programs for health education.

What Rational Management (justified) of chemotherapeutics means for patients is that treatments with chemotherapeutics are consistent with their clinical needs; also, that they are given in appropriate doses, for as long as needed, and at the lowest possible financial cost to the patients.

Irrational Administration (unjustified) is the administration of chemotherapy in a way that does not comply with the therapeutic standard [1]. It is considered that worldwide, around $50 \%$ of drugs are administered, prescribed or used inappropriately, while $50 \%$ of patients fail to recover adequately.

\subsection{Aim of Research}

The main purpose of this research on the administration of chemotherapeutics is to rationalize the administration of chemotherapy by nurses to patients at the University Clinical Center of Kosovo. In more detail, the paper argues that it analyzes the good and bad sides of the work of nurses who are dedicated to the application of chemotherapeutics at UCCK. The study will describe the current situation, trends in prescribing chemotherapeutics and their application at different levels of the health system.

The study also assesses the suitability of chemotherapy administration and generally assesses the association between prescribing data and prescribing indications. This assessment aims to improve the quality of health care, given the growing interest in assessing the economic impact of healthcare and medical technology.

The common forms of unjustified administration of chemotherapeutics.

Administration of many chemotherapeutics to the same patient;

Inappropriate administration of chemotherapy, often in incorrect doses, or for non-bacterial infections;

Failure to prescribe therapeutics according to clinical guidelines;

Self-treatment, with chemotherapy to be given by prescription only [2].

\subsection{What Are Chemotherapeutic Agents (Cytostatic)}

Chemotherapeutic drugs are used to block the growth of cancer cells. They achieve this by influencing the metabolism of cells during cell cycle, causing division and reproduction of cells to become inhibited. Chemotherapeutic can be classified according to their mechanisms of action and their attack points [3]. Mechanisms of Action are more likely to lead to carcinogenic, mutagenic, and teratogenic. Therefore, pregnant women should avoid any contact with chemotherapy drugs. This is required by law in most European countries, but not in all countries (ex. USA) [4].

Since cancer cells hardly differ physiologically from healthy cells, chemotherapy drugs do not specifically affect only cancer cells, but all dividing cells. Therefore, substantial effects can occur such as nausea, hair loss and immuno- 
suppression. These unwanted side effects occur not only in patients treated with chemotherapeutics, but also pose a risk to health staff, especially when they are involved in the preparation of the chemotherapeutic drug (pharmacy) and administration (Nursing). Moreover, it can affect personnel involved in the distribution, transportation, and disposal of chemotherapeutic drugs as well as the technical and laboratory staff [5] (for example, during maintenance of safety cabinets or the patient's blood or urine [6] analysis).

\subsection{History of the Hematology Clinic in HUCSK}

In 1978 it was established for the first time in Kosovo as the Hematology Service which was formed by Prof. Shaban Geci [7]. Initially worked as two doctors, then added four doctors for the department. In 2013 it was transformed into a Hematology Clinic. The Clinic of Hematology, which operates within HUCSK (Hospital and University Clinical Service of Kosova) consists of two departments-Department of Clinical Hematology and Department of Blood-Oncology. This clinic possesses 31 beds. The clinic consists of one matron of the clinic which has supervision 2 matron of units and other nurses, one matron of Clinical Hematology Department which supervises seven nurses, one of which works Clinics, one matron of Blood-Oncology Department which supervises six nurses.

At the Clinic for Hematology exists semi-intensive with four beds, where the Chemotherapy applies. The clinic has two employed professors of the Internal Medicine-Hematology, a hematologist and one specialist in internal medicine. This clinic has 15 nurses. In this clinic diagnosed, treated the sick with the pathology of various hematological and blood-oncology. Also the clinic treated patients with acute leukemia.

\section{Methods}

The study was prospective and was conducted in UCCK. The subject of analysis was the facilities available for hospitalization and administration of chemotherapists at UCCK, the existence or not of a written protocol, the available technical equipment and the availability of a consultant. Quantitative methods were used where we conducted surveys with nurses administering chemotherapists in different departments of the UCCK. Analytical methods were also used where we analyzed various documents and standards relating to the use of chemotherapists. A descriptive method was also used in this paper, where we described various theories of competent authors (Thomas Connor, Robert Mclauchlen, Mark Ba, Yk Change, Te Vaughn) [8] [9] [10] [11] on the application of chemotherapeutics and the role of nurses in this process.

\subsection{Samples}

Sample in this research are 33 health workers dealing with the administration of chemotherapy at UCCK. Although seemingly reflected by a small number of respondents, this number is the total of health workers who are engaged in the administration of chemotherapy at UCCK; therefore, there was no other option 
to increase the number of respondents. I considered that the inclusion of other participants in the survey will lessen the accuracy of the information expected for this research. Selection of the sample was intentional, where the criteria for the survey have just been health workers who are engaged in the administration of chemotherapy at UCCK.

\subsection{Instrument}

The measurement tool in this paper is a survey guide, containing 21 structured questions, which gives the respondent the opportunity to round out one of the alternatives given in each question. This means that each respondent had the same questionnaire, the same question, and the same alternatives to answer. The instrument was developed based on previous theories and standards of chemotherapy administration, where it was then formulated and finalized with the help of a mentor. For the construction of the questionnaire, we mainly relied on the title of the paper, the purpose and hypotheses of this paper, so that each question was related to the topic we were exploring.

\subsection{Procedure}

To conduct the survey first, I obtained permission from the Hematology, Oncology and Pediatrics Department. I then informed the respondents about the purpose of the research. The respondents were not pressured to provide the correct answers, and each one responded without bias, providing the deserved approval. After the survey, I collected and interpreted the data using the Excel application. Through this program, I generated charts and tables where I presented them as a percentage. Questionnaire administration time was 30 minutes.

\subsection{Ethical Principles}

After the topic was approved by the AAB College administration, I signed the Statement of Academic Honesty. I stated and always adhered to the principle that I would refer accurately to all sources of literature used in the work, and I was also aware of the consequences of false statements.

Even with respect to the survey, I adhered to ethical principles where I gave confidentiality to all respondents and promised them that the survey data would only be used for master purposes.

\section{Results}

\section{Results of the Quantitative Research}

If we look a Figure 1, we can see that the age of the respondents in this survey is as follows: $12 \%$ belong to 21 - 30 years, $40 \% 31$ - 40 years, $21 \%$ of those surveyed 41 - 50 years. Years, $24 \%$ of respondents are 51 - 60 years old, while $3 \%$ are 61 65 years old.

When it comes to the gender of the respondents, $18 \%$ of the respondents are male and $82 \%$ are female. This clearly shows that in the departments or clinics 
where chemotherapy is administered, the female gender is significantly more involved in this issue.

Regarding the education of the respondents, $46 \%$ have high school, $33 \%$ have a university degree, while $21 \%$ have a master's degree. None of the subjects selected the doctoral option.

Respondents were asked if they had received some training in the use of cytostatic. Out of the total number of subjects, $33 \%$ of them received training, while $67 \%$ did not receive training in cytostatic administration.

If they do regular check-ups because they give cytostatics, $100 \%$ of respondents say they do not do regular check-ups. None of the respondents stated this, which is a bit worrying.

Respondents were asked how many nurses administer cytostatics at the clinic where they work. $48 \%$ of respondents indicated that $1-5$ nurses were involved in cytostatic administration, $52 \%$ of respondents said that $1-15$ nurses were involved in cytostatic administration, while no alternatives were selected by $6-10$ nurses and 16 or more nurses. See Figure 2.

One of the questions that we asked the respondents was whether there is a dedicated space for administration of cytostatic. 55\% of respondents confirm that they have the dedicated space, while $45 \%$ of respondents deny this.

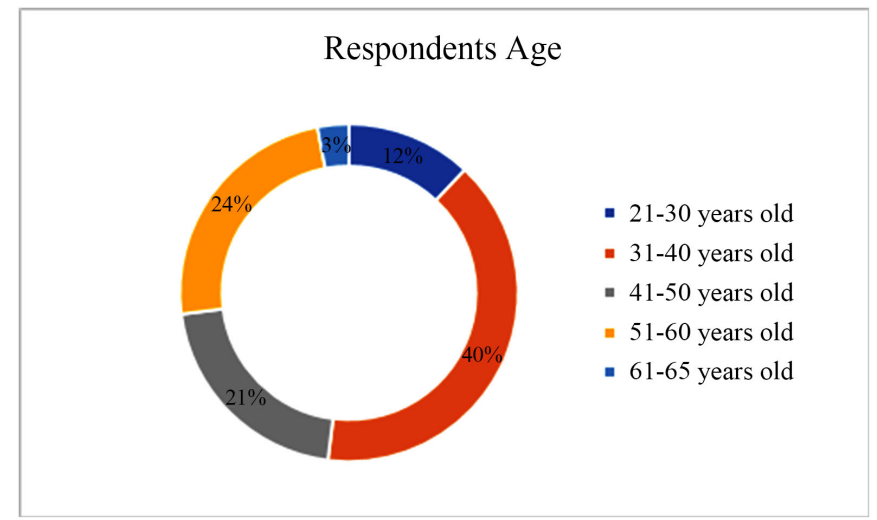

Figure 1. Respondents age.

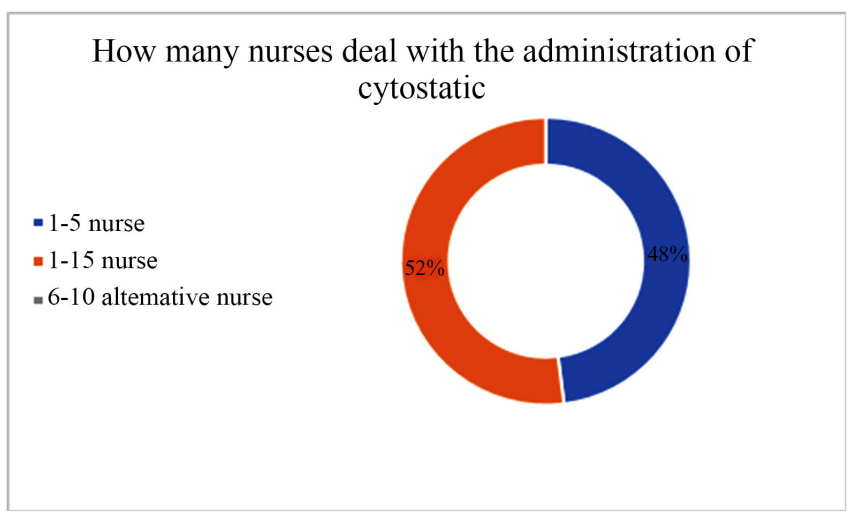

Figure 2. The number of nurses who handle with the administration of cytostatic. 
Respondents were asked where the medication was stored before administration. $61 \%$ of respondents state that they are kept at a central pharmacy, 39\% of respondents state that they are kept in a doctor's department, while none of the respondents state that they are in a patient.

Respondents were also asked where the medication was prepared before their administration. $18 \%$ of respondents declared in the central pharmacy, $58 \%$ of respondents declared in the pharmacy, while $24 \%$ of those declared in the hospital room.

Whether the drug is transported in specially marked containers, $42 \%$ of respondents state that, while $58 \%$ of the respondents state that the drug is not transported in specially marked containers.

One of the questions we asked respondents was whether there was a special space for the administration of cytostatic. 55\% of respondents confirm this, while $45 \%$ deny it.

Respondents were asked if there were special locker rooms in which staff managing cytostatic changed before and after administration. 100\% of respondents thus denied the conclusion that no clinic in the UCCK managing cytostatic has special changing rooms for staff administering cytostatic.

One of the questions we asked was what was the entrance to the room where the cytostatic were given. $64 \%$ of respondents say access is restricted to staff only, $15 \%$ of respondents say access is free for all healthcare professionals, while $21 \%$ of respondents say access is free for everyone.

Regarding the food and drink consumed in the room where the cytostatic are given, $39 \%$ of respondents say that they are allowed to eat and drink, while $61 \%$ deny it.

If there were written instructions on how to administer cytostatic, $82 \%$ of respondents stated that there were written instructions on how to administer cytostatic, while $18 \%$ denied it.

One question in our study related to where cytostatic are dumped after administration. $39 \%$ of respondents stated that they were thrown into ordinary baskets, while $61 \%$ said that they were thrown into baskets specifically intended for cytostatic waste management.

Does professional experience affect nurses' mistakes, $79 \%$ of respondents agree, while $21 \%$ disagree.

Subjects were asked whether they were preparing the patient before intramuscular or intravenous injection. In this question, $100 \%$ of the respondents stated that they were preparing the patient before intramuscular or intravenous injection.

Have the subjects ever been pierce during intramuscular or intravenous therapy, $64 \%$ of respondents claimed to have been pierce during intramuscular or intravenous therapy, while $36 \%$ denied.

Respondents were asked if they were mistaken for a lack of pharmacological knowledge. $58 \%$ of respondents admit this, while $42 \%$ of respondents deny this by suggesting that they did not make a mistake because of a lack of pharmaco- 
logical knowledge.

Among the questions asked was whether the respondent ever had an infection during chemotherapy. $76 \%$ of respondents confirm this, while $24 \%$ deny it.

The last question was whether extended working hours had a negative impact on their work. $79 \%$ of respondents say that extended working hours affect their work, while $21 \%$ of respondents deny it.

\section{Discussion}

\subsection{Discussion of the Results of Quantitative Research and Their Comparison with European Practices and Standards}

According to ISOPP standards for the use of cytostatic, all personnel involved in the treatment of cytotoxic drugs, including transportation, storage and cleaning of facilities, must be trained in the use of personal protective equipment and safe treatment procedures. These staff members should be evaluated regularly to verify adherence to procedures. Cytotoxic drugs should be treated and stored by pharmacy-trained staff [12].

The other finding is that none of the subjects do regular screening because they apply cytostatic, which is quite worrying. According to ISOPP standards for the use of cytostatic, personnel responsible for engaging in parenteral cytotoxic drug manipulation should undergo basic testing that includes assessment of indicators such as complete blood screening, liver function tests, urea, creatinine and electrolytes.

These measurements can then be used to compare any of the following measures taken routinely or after accidental exposures. Regular follow-up, which includes a thorough blood test and differentiation, should be offered at least six months apart. Institutions should have a written policy for the initial and regular monitoring of staff involved in the preparation of cytotoxic drugs [13].

Generally speaking, the number of nurses involved in the administration of cytostatic in the clinic where they work is very small where there is a need for increased staffing.

It became clear that before their administration, drugs were stored in central pharmacies and partly in pharmacies. Even when these drugs are prepared before administration, they are generally prepared in the physician ward, with exceptions in the hospital room.

It is worrying that research results show that the drug is not transported in specially marked containers. However, the space dedicated to delivering cytostatic is solid. According to ISOPP standards for the use of cytostatic, primary containers and cartons should be designed to minimize the risk of fracture by the use of explosion-proof materials. These include bottles made of indestructible plastic material, glass bottles fixed in specially designed plastic containers, or glass bottles wrapped in plastic to prevent contamination in the event of glass breaking [14].

One thing to note in the research is that no clinic at UCCK that provides cy- 
tostatic has special wardrobes for staff applying cytostatic. Even for the conditions in which the cytostatic is given. Most of the respondents stated that the conditions were poor and did not even meet the minimum criteria for such a room.

The results show that in a room where cytostatic are administered, the entrance is restricted to staff only, in some small cases entry is free for all healthcare professionals, while very few state that entry is free for all.

It is a worrying finding that food and drink are allowed in these areas. This is despite the fact that there are written instructions on how to administer cytostatics. By ISOP standards, it is strictly forbidden to eat, drink, chew or use cosmetics. In addition, staff at the training center may not wear rings, earrings, bracelets or other jewelry.

The results show that nurses think that professional experience influences their mistakes. According to Mrayyn and others, although medications can be caused by the mistakes of all members of the healthcare team, mistakes in the nurse are most common. The reason is that nurses perform most of the medical orders and spend about $40 \%$ of their time in the hospital administering medication [15].

They also show that they are sometimes punctured during intramuscular or intravenous therapy. The results confirm that they made mistakes in the absence of pharmacological knowledge. According to Mason, nurses have little knowledge of drugs; especially in calculating drug dosage but also in managing pharmacological knowledge. Poor knowledge can be the result of deficiencies in nursing primary education or lack of ongoing maintenance training during work years [16].

Another issue that was observed in the study was that the subjects had an infection during the administration of chemotherapy. They claim that extended hours affect their work.

\subsection{Verification of Hypotheses}

In this thesis, two hypotheses have been put forward which we have been able to validate through quantitative research and literature review.

H1. Nurses' knowledge of chemotherapeutic administration affects their errors in working with the patient.

This hypothesis is confirmed by quantitative research where respondents were asked if they had made mistakes in the absence of pharmacological knowledge. $58 \%$ of respondents admit this. Hypothesis is also supported by the theory of Marylin, who find that medication errors can be caused by all members of the health care team; medical nursing errors are the most common. The reason is that nurses carry out most of the medical orders and spend about $40 \%$ of their time in the hospital administering medications [17].

H2. Overtime negatively affect in nurse's performance in the admirations of cytostatic.

The second hypothesis is also tested by asking whether the overtime negative- 
ly affect the nurse's performance, with $79 \%$ of respondents stating that the extended working hours do affect their performance. The hypothesis is also supported by the ISOPP Standards for the use of cytostatic, where according to them, a sufficient number of staff members should be available to ensure the expected workload.

\section{Conclusions}

This master's thesis represents the good and bad sides of the work of nurses who are dedicated to the application of chemotherapists at UCCK. The study describes the current situation, trends in the prescribing of chemotherapeutics and their application at different levels of the health system in the UCCK.

In this paper, it has become clear that the development of policies on the application of chemotherapeutics has increased the demand for deeper knowledge in this field. In this way, there was a need to identify trends in chemotherapy consumption and prioritize the interests of regulatory bodies, and create health education programs.

Literature review cities chemotherapeutic drugs as drugs used to block the growth of cancer cells. They do this by affecting cell metabolism during the cell cycle, so that they resemble cell division and cell reproduction. Chemotherapeutics can be classified according to their mechanisms of action and their points of attack.

It was announced that the Hematology Service was first established in Kosovo in 1978, formed by Prof. Dr Shaban Geci. Initially, two doctors worked, and then four doctors were added to work in the department. In 2013, he was converted to the Hematology Clinic.

In terms of staffing, this master's thesis stipulates that all staff involved in the preparation and administration of cytotoxic drugs must have a qualified qualification or must have certified training in accordance with local regulations. Practical evaluation should be conducted on a regular basis for all staff preparing and administering chemotherapy. All personnel involved in cytotoxic drug treatment, including transportation, storage and cleaning of facilities, must be trained in the use of personal protective equipment and safe treatment procedures. These staff members should be evaluated regularly to verify adherence to procedures. Cytotoxic drugs should be handled and stored by pharmacy-trained personnel.

One thing found in the study is that no clinic at UCCK that manages cytostatic has special wardrobes for staff applying cytostatic. Even for the conditions in which cytostatic is given. Most of the respondents stated that the conditions were poor and did not even meet the minimum criteria for such a room. It is also worrying that food and drink are allowed in these areas.

\section{Acknowledgements}

It is well known that during the process of writing the thesis, nothing would be 
possible without the help of lecturers, colleagues, institutions, etc. First of all, I am grateful to the subject mentor, Dr. Sc. Luan Jaha, who found time and was willing at any moment to help me with his professional advice.

A special recognition deserves also the health staff of Clinical Hematology, Oncology Clinic and Clinic of Pediatrics-Pediatrics Department-Hematology, who responded positively to my request for conducting surveys. I also thank my family for moral support all the time.

\section{Funding}

The study was financed by author

\section{Conflicts of Interest}

The authors declare no conflicts of interest regarding the publication of this paper.

\section{References}

[1] Casey, K., Fink, R., Frugman, M. and Propst, J. (2004) The Graduate Nurse Experience. The Journal of Nursing Administration, 34, 303-311. https://doi.org/10.1097/00005110-200406000-00010

[2] Cohen, H., Robinson, E.S. and Mandrack, M. (2003) Getting to the Root of Medication. Nursing, 33, 36-45. https://doi.org/10.1097/00152193-200309000-00037

[3] Sessink, P., Boer, K., Scheefhals, P., Anzion, R. and Bos, R. (1992) Occupational Exposure to Antineoplastic Agents at Several Departments in a Hospital. Environmental Contamination and Excretion of Cyclophosphamide and Ifosfamide in Urine of Exposed Workers. International Archives of Occupational and Environmental Health, 64, 105-112. https://doi.org/10.1007/BF00381477

[4] Falck, K., Grohn, P., Sorsa, M., Vainio, H., Heinonen, E. and Holsti, L. (1979) Mutagenicity in Urine of Nurses Handling Cytotoxic Drugs. The Lancet, 313, 1250-1251. https://doi.org/10.1016/S0140-6736(79)91939-1

[5] Shskuk. Hematology Clinic. http://shskuk.org/klinika-e-hematologiise/

[6] Chabner, B.A., Allegra, C.J., Curt, G.A. and Calabresi, P. (1961) Antineoplastic agents. In: Hardman, J.G. and Limbird, L.E., Eds., Goodman, \& Gilman's The Pharmacological Basis of Therapeutics, McGraw-Hill, New York, 1233-1287.

[7] Leape, L.L. and Bates, D.W. (1995) Systems Analysis of Adverse Drug Events. ADE Prevention Study Group. The Journal of the American Medical Association, 274, 35-43. https://doi.org/10.1001/jama.1995.03530010049034

[8] Prot, S., Fontan, J.E. and Alberti, C. (2005) Drug Administration Errors and Their Determinants in Pediatric in-Patients. International Journal for Quality in Health Care, 17, 381-389. https://doi.org/10.1093/intqhc/mzi066

[9] Wilkins, K. and Shields, M. (2008) Correlates of Medication Error in Hospitals. Health Reports, 19, 7-18.

[10] Zapf, D. and Brobeck, F.C. (1992) Errors in Working with Office Computers: A First Validation of a Taxonomy for Observed Errors in a Field Setting. International Journal of Human- Computer Interaction, 4, 311-339. https://doi.org/10.1080/10447319209526046

[11] Connor, T., McLauchlan, R. and Vandenbroucke, J. (2007) ISOPP Standards of Prac- 
tice Safe Handling of Cytotoxics. Journal of Oncology Pharmacy Practice, 13, 1-81.

[12] McGillis, H.L. and Doran, D. (2004) Nurse Staffing Models, Nursing Hours, and Patient Safety Outcomes. The Journal of Nursing Administration, 34, 41-45. https://doi.org/10.1097/00005110-200401000-00009

[13] Mason, D.J. (2005) To Forgive, Divine: It Is Time to Drop the Veil of Secrecy about Dislosing Errors. The American Journal of Nursing, 105, 11. https://doi.org/10.1097/00000446-200512000-00001

[14] Nursing and Midwifery Council (2006) Medicines Management. A-Z Advice Sheet. NMC, London.

https://www.nursingtimes.net/clinical-archive/medicine-management/the-administ ration-of-medicines/288560.article

[15] Blegen, M.A., Vaughn, T.E. and Goode, C.J. (2001) Nurse Experience and Education: Effect on Quality of Care. The Journal of Nursing Administration, 31, 33-39. https://doi.org/10.1097/00005110-200101000-00007

[16] Mrayyon, M.T., Shishani, K. and Al-faouri, L. (2007) Vepër e cituar. 659-670.

[17] Seki, Y. and Yamazaki, Y. (2006) Effects of Working Conditions on Intravenous Medication Errors in a Japanese Hospital. Journal of Nursing Management, 14, 128-139. https://doi.org/10.1111/j.1365-2934.2006.00597.x 


\section{Questioner}

1) Demographic Description. Please tell us something about yourself?
A) Your age
B) Gender: M F
C) Education level
i) Hight school
ii) Bachelor
iii) Master
iv) Doctorate
D) Did you receive training in the administration of cytostatic?
i) Yes
ii) No
E) If you completed the training when, where and for what duration? i)
ii)
F) Do you do regular (systemic) check-ups because you administer cytostatic? i) Yes
ii) No

\section{2) Descriptions for your job and practices}
A) How many nurses deal with the administration of cytostatic?
B) Where is the medication stored before being administered?
i) Central pharmacy
ii) The ward pharmacy
C) Where does the medication prepare before administration?
i) Central pharmacy
ii) The ward pharmacy
iii) In the patient's room
D) Does the medication transported in a specially marked container?
i) Yes
ii) No
E) Is there dedicated space for the administration of cytostatic?
i) Yes
ii) No
F) Are there special cabinets in which personnel administering cytostatic are replaced before and after administration?
i) Yes
ii) No
G) The room in which the cytostatic are administered is a:
i) $10 \mathrm{~m}^{2}$
ii) Easy to clean
iii) With a floor that rises up to $10 \mathrm{~cm}$ on the wall
iv) Condition is poor
$\mathrm{H})$ In the room where the cytostatic are administered the entrance is 
i) Limited to personnel only

ii) Unrestricted to all health workers

I) Is it permissible to consume food and drinks in the room where the cytostatic are administered?

i) Yes

ii) No

J) Are there written instructions on how to administer cytostatic?

i) Yes

ii) No

K) After the cytostatic are given they are thrown in:

i) Waste baskets

ii) Specially dedicated baskets for cytostatic

L) Does professional experience effect on nurses' mistakes?

i) Yes

ii) $\mathrm{No}$

M) Do you prepare the patient before applying intramuscular or intravenous injection?

i) Yes

ii) No

N) Have you ever pierced yourself while applying intramuscular or intravenous therapy?

i) Yes

ii) $\mathrm{No}$

O) Dose overtime effect negatively in your performance?

i) Yes

ii) $\mathrm{No}$ 